\title{
O processo de comunicação organizacional interna: um estudo realizado em uma Associação Comercial e Empresarial do Paraná
}

Caroline Monteiro ${ }^{I}$

http://orcid.org/0000-0001-9028-5545

Marcos Roberto Kuh II

http://orcid.org/0000-0001-6578-5804

Juliane Sachser Angnes ${ }^{\text {III }}$

http://orcid.org/0000-0002-4887-7042

${ }^{I}$ Universidade Estadual do Centro Oeste, PR, Brasil.

Mestra em Administração.

${ }^{I I}$ Universidade Estadual do Centro Oeste, PR, Brasil.

Pós-doutor em Contabilidade.

III Universidade Estadual do Centro Oeste, PR, Brasil.

Pós- doutora em Administração.

http://dx.doi.org/10.1590/1981-5344/3975

Este artigo, apresenta resultado de pesquisa que objetivou compreender o processo de comunicação organizacional interna de uma Associação Comercial e Empresarial localizada no Paraná. Trata-se de um estudo de caso de natureza descritiva, de abordagem metodológica qualitativa com suporte quantitativo; primeiramente, realizou-se a análise quantitativa dos dados, de forma não-paramétrica por meio da Análise de 
Cluster. Já na análise qualitativa realizou-se a análise focada no conteúdo. O processo de comunicação interna, de acordo com a pesquisa quantitativa, acontece de maneira satisfatória na organização pesquisada, pois, fatores possuem médias elevadas e apenas alguns pontos específicos de possíveis problemas (variáveis com médias baixas). A pesquisa qualitativa aponta que este processo possui itens que deveriam ser aprimorados, tais como, 0 fator em que os respondentes afirmam não possuírem acesso a determinadas ferramentas de comunicação interna e/ou ao afirmarem estar descontentes com a não disponibilização destas ferramentas. Assim, torna-se extremamente necessário a disponibilização de todas as ferramentas de comunicação interna aos funcionários, visto que é por meio da comunicação interna que acontece o relacionamento contínuo, ou seja, se a comunicação interna for falha, poderá haver um conflito durante a realização da tarefa e que poderá refletir no cliente final.

Palavras-chave: Comunicação organizacional. Comunicação interna. Processo de comunicação. Estratégia organizacional.

\section{The process of internal organizational communication: a study done on a Commercial and Business Managment Association of Paraná state}

This article presents a research results that aimed to understand the internal organizational communication process of the Commercial and Business Association of Paraná State. This is study case of a descriptive nature, qualitative research with quantitative; first, its noticeble that the quantitative analysis of data from nonparametric, the statistical test selected for the process of data analysis was Cluster Analisys. However, for the 
qualitative analysis, focusing on content, the internal communication process, according to quantitative research, takes place in a satisfactory manner, because all the factors have high average. Thus, they identified only some specific points of potential issues (variables with low average). Already the qualitative research shows that have some items that should be improved, such as the factor that respondents say they do not have access to certain internal communication tools and / or claiming to be unhappy with failure to provide these tools. Like this, it's suggested that these Internal communication tools should be made available to all workers/employees, since it is through the internal communication happens continuous relationship. Namely, if the internal communication for failure, there may be hum conflict during realization task and que will be able to reflect the end client.

Keywords: Organizational Communication. Internal communication. Process of communication. Organizational strategy.

Recebido em 26.02.2019 Aceito em 05.10.2020

\section{Introdução}

A comunicação organizacional interna, vinculada à estratégia, permite o compartilhamento de informações propiciando, assim, resultados positivos à organização visto que a gestão estratégica da comunicação é uma ferramenta que se preocupa em auxiliar a empresa na articulação de suas atividades almejando atingir seus objetivos funcionais.

Desta forma, a comunicação interna da empresa contribui na definição e efetivação de metas e objetivos, além de promover a integração e o equilíbrio entre os elementos que a compõe pois, quando bem direcionada, permite aos indivíduos a renegociação das categorias, as interpretações e as experiências compartilhadas (PIMENTA, 2010; HALL, 2004). Isso significa que todos os componentes das organizações, em sua ação cotidiana, são protagonistas da expressividade da filosofia organizacional (NASSAR, 2008). 
Para Ricardo (2009) é o processo através do qual os membros de uma organização reúnem informação pertinente sobre ela própria e sobre as mudanças que ocorrem no seu interior; além disso, permite às pessoas gerar e partilhar informações, que the dão a capacidade de cooperar e se organizarem.

Em outras palavras, considera-se que a comunicação interna seja o ponto de partida para o alinhamento do discurso de uma organização. Ou seja, realizar um processo comunicativo eficiente entre a organização e seu público interno não é um procedimento simplista, nem tampouco fácil, isso porque envolve o comprometimento de ambas as partes, que além de realizarem este processo de forma dinâmica e flexível, precisam estar conscientes sobre a relevância disto.

Para tanto a pesquisa, pretendeu investigar 0 seguinte questionamento: Como ocorre o processo de comunicação organizacional formal interno de uma Associação Comercial e Empresarial do Paraná? Sendo assim, o objetivo geral desta pesquisa propôs compreender o processo de comunicação organizacional interna de uma Associação Comercial e Empresarial localizada no Paraná.

Nota-se que há, atualmente, um espaço mais evidente na estrutura organizacional do profissional apto a gerenciar informações e serviços com capacidade de organizar e administrar todas as informações com qualidade e credibilidade no trabalho, por isso a necessidade de aprofundamento de estudos e pesquisas empíricas sobre este tema.

Assim, a relevância deste estudo se dá pelo fato de o processo comunicacional nortear todas as organizações. Sabe-se que a organização não existe fora das práticas comunicativas de seus membros: elas são produzidas e reproduzidas nos processos discursivos e dialógicos que formam, ao mesmo tempo, lugares de controle e de potência. Nesse sentido, as experiências compartilhadas em diálogo deveriam produzir algo culturalmente novo e não apenas se configurar como apresentação/negociação/justificativa de interesses (MARQUES; MAFRA, 2013).

Além disso, a realização da pesquisa se justifica porque permitiu agregar a prática aos estudos acadêmicos, visto que a comunicação interna se relaciona à sobrevivência das organizações por estar presente em praticamente todas as atividades do cotidiano empresarial. $\mathrm{Na}$ academia há poucos estudos que visam discutir a comunicação organizacional interna alinhavada aos problemas e conflitos cotidianos passíveis de serem resolvidos desde que o processo de melhoria esteja em pauta. 


\section{Comunicação organizacional}

Haja vista que a sociedade exige dos indivíduos, uma adaptação à nova realidade, no sentido de procurar e implantar novas formas de comunicação com vistas a facilitar os processos interativos, pode-se inferir que a vantagem competitiva, nas organizações, na atual era da informação, é decorrente do conhecimento (MATEUS, 2014; TAVARES, 2010).

As novas tecnologias de informação e comunicação, existentes em todos os níveis de informação organizacional, principiam a transformação de processos e a mudança das maneiras de interação e de relação com o meio. Neste sentido, verificam-se novos procedimentos cotidianos por meio de uma nova cultura organizacional que se origina na sociedade (LIMA, 2004).

No tocante ao desenvolvimento dos conceitos de comunicação organizacional, introduziram-se conhecimentos sobre a importância da comunicação, tendo a questão comunicacional adquirido um papel determinante nas organizações (RICARDO, 2009). Assim, nota-se que as definições têm sido abordadas de diferentes maneiras pelos estudiosos desta área de conhecimento; cada um deles tenta atribuir uma explicação ao significado de comunicação organizacional, envolvendo tanto os fatores teóricos quanto os fatores profissionais da área (REBECHI, 2009).

Processos de comunicação em organizações fornecem interessantes conceitos e práticas de diálogo a serem considerados. Em primeiro lugar, a globalização dos negócios, o crescimento das mulheres e das diferentes etnias no mercado de trabalho tornam ativa a diversidade. Em segundo lugar, as diferenças de poder e de relações hierárquicas são partes visíveis da maioria das grandes organizações. Então, nesse contexto, a comunicação apresenta-se como um recurso estratégico, pois as formas de interação nas organizações têm um viés em direção à tomada de decisões (DEETZ; SIMPSON, 2004).

Para tanto, entender a importância do processo de comunicação, no momento oportuno, com a finalidade de alcançar o objetivo almejado, é um desafio para as organizações (MELO, 2010). Por isso, as organizações precisam "reunir pessoas qualificadas, confiáveis e com elevado espírito de trabalho em equipe, capazes de atuar remotamente e ter ampla autonomia para tomada de decisões em relação às tarefas" (GUIMARÃES; SQUIRRA, 2007, p.46).

Nessa perspectiva, a comunicação é uma dimensão de interação social, ou seja, baseia-se e reproduz a significação de recursos de um sistema social, mas sempre em contextos práticos (MCPHEE; IVERSON, 2009). Sendo assim, a comunicação não deve ser encarada como um processo centralizado na emissão da mensagem. É na recepção dela que 
se define o êxito da comunicação. No âmbito da comunicação organizacional, significa que só podemos mensurar sua efetividade se conseguimos, de alguma maneira, capturar a interpretação das mensagens pelo público-alvo (SOARES, 2008).

A comunicação organizacional pode ser interna ou externa. Neste estudo, a comunicação interna é abordada, a seguir.

\subsection{Comunicação organizacional interna}

Para Lemos (2011) a comunicação interna é um elemento da comunicação organizacional. Direciona-se a um público estratégico, fundamental das organizações: seus funcionários que, ligados à empresa por meio de vínculos de trabalho, afetam ou são afetados pelos processos de comunicação interna enquanto vão no encalço de sua missão e objetivos.

Dito de outra forma, Marchiori (2008a, p. 213) afirma que:

A comunicação interna [...] é uma ferramenta estratégica que estimula o diálogo entre lideranças e funcionários. Oportuniza a troca de informações via comunicação, contribuindo para a construção do conhecimento, o qual é expresso nas atitudes das pessoas [...]. Promove, portanto, a interação social e fomenta a credibilidade, agindo no sentido de manter viva a identidade de uma organização.

Consoante com isso, Corrado (1994) salienta que a comunicação organizacional interna não se concentra mais na mera transmissão de informações, mas sim, na mudança do comportamento dos funcionários de maneira que todos se sintam envolvidos com a organização e possam executar suas atividades com satisfação.

Scroferneker (2006) afirma que a comunicação interna seja composta por trocas, atos e ações compartilhadas, implica interação, diálogo e respeito mútuo do falar e deixar falar, do ouvir e do escutar, do entender e do fazer-se entender e principalmente do querer entender.

Nesse sentido, conforme Marchiori (2010), é necessário ver a comunicação interna como um processo, como um ângulo de maior desenvolvimento, como algo que provoca conhecimento às pessoas, que transforma estruturas e comportamentos.

Nesta perspectiva, observa-se que a comunicação organizacional interna envolve as diversas formas de comunicação adotadas pela organização para inter-relacionar-se com seus públicos, visto que o processo "comunicar" não significa somente informar, mas também, interagir e favorecer a troca de mensagens embasado em sentimentos e experiências de vida. Por isso, as comunicações podem ser capazes de 
afetar positivamente e serem, de fato, envolventes e efetivas e, para criar novas formas de comunicação interna, é preciso antes compreender o funcionário como potencial humano e entender suas formas de recepção e expressão (SCROFERNEKER, 2006; RIBEIRO, 2014).

Desta maneira, pode-se inferir que a comunicação interna possui importância estratégica devido ao fato de o público interno estar suscetível à incorporação de novos conceitos e práticas que podem garantir o desempenho da organização e a satisfação dos clientes (ARAÚJO FILHO, 2003).

\subsection{A comunicação organizacional: aspecto relevante na gestão estratégica}

Diante de um cenário de grande competitividade no mercado, para um maior comprometimento dos funcionários exige-se um comportamento de maior envolvimento do colaborador em relação ao funcionamento da organização (REBECHI, 2009). O século XXI caracteriza-se pelo predomínio da categorização do trabalho intelectual, pela fragmentação do conhecimento e pela excessiva predominância das especializações (ANDRADE, 2013).

Conforme Nassar (2008), as transformações decorridas na esfera do desenvolvimento socioeconômico, ao longo de décadas recentes, e o processo de globalização contemporâneo fazem sugerir que o processo comunicacional nas organizações também passou por mutações.

Diante deste contexto, as organizações e as suas estratégias são socialmente construídas, legitimadas e institucionalizadas nas práticas sociais e interações. Assim, a comunicação é uma realidade inerente ao processo de estratégia enquanto uma prática nas organizações contemporâneas (MARCHIORI et al., 2010).

A comunicação interna, alinhada à estratégia corporativa, à missão e visão organizacionais, busca a sinergia para a consecução das metas individuais e organizacionais, para a geração de valor e o afunilamento nas relações administração-funcionários. Para tanto, os processos de comunicação interna que favoreçam o relacionamento interpessoal, nas organizações, são essenciais para possibilitar o engajamento das relações no ambiente de trabalho (BEM, 2013).

Por meio deste posicionamento, a comunicação organizacional interna torna-se indispensável e essencial podendo ser vista como uma estratégia empresarial, auxiliando no fortalecimento da imagem da empresa e conquistando mercado e maior lucratividade. Cada funcionário, ao receber informações, tende a se manifestar sobre elas. Por isso, representa um potencial receptor e difusor de opiniões, favoráveis ou não. Destaca-se, então, a importância da comunicação organizacional na geração de conhecimento e compartilhamento de informações, 
estimulando os indivíduos a visualizar que a sinergia pode contribuir significativamente para a maximização dos resultados organizacionais e minimização dos impactos negativos possíveis (ARAUJO FILHO, 2003).

Sendo assim, observa-se que a comunicação interna, vinculada à estratégia, pode valorizar os relacionamentos e permitir a geração de vínculos de confiança, responsabilidade, credibilidade e fidelidade, evidenciados por meio do nível de engajamento dos indivíduos na organização (BEM, 2013).

A área da comunicação organizacional, sob a ótica da gestão estratégica, está preocupada em pensar estratégias comunicacionais que possam acrescentar valor aos negócios, propiciando, assim, resultados positivos (REBECHI, 2009).

Diante deste contexto, a comunicação é visualizada como fator essencial ao processo de entendimento da organização em si mesma e no desenvolvimento de seus relacionamentos por envolver vários processos nos distintos níveis organizacionais. Para tanto, a influência dos processos comunicacionais no desenvolvimento das estratégias é abordada como ferramenta, sendo sua importância direcionada à forma com que se comunica a estratégia (MARCHIORI, 2011).

\section{Metodologia}

A pesquisa realizada trata-se de um estudo de caso, de caráter descritivo. Para Triviños (2010) o estudo de caso proporciona o conhecimento detalhado de uma determinada realidade em que os resultados obtidos podem tanto permitir quanto formular hipóteses para o encaminhamento de outros estudos.

Quanto à abordagem, o estudo realizado configurou-se como sendo uma abordagem de pesquisa qualitativa com suporte quantitativo. $\mathrm{Na}$ primeira parte da pesquisa, para medição quantitativa, buscou-se atingir o universo de 26 funcionários que fazem parte do quadro funcional da Associação. Propôs-se inicialmente que o instrumento de coleta de dados (questionário) abrangesse todos os funcionários da organização, em estudo, objetivando-se ter uma visão mais concreta da realidade organizacional por eles vivenciada.

O questionário utilizado refere-se a uma adaptação de Tavares (2010) já validado no Brasil e ajustado às situações do contexto desta investigação. Cabe explicitar que o mesmo é composto por 33 questões em relação à percepção do respondente sobre a comunicação interna existente na organização em estudo, além de cinco questões relacionadas ao perfil do sujeito de pesquisa contemplando as seguintes informações: 1) idade, 2) estado civil, 3) gênero; 4) grau de escolaridade e, por fim, 5) tempo de trabalho na instituição. 
Os agrupamentos foram definidos e nominados de acordo com as características comuns das variáveis que as compõem: Agrupamento "cooperação e objetivos organizacionais" (Tabela 1); agrupamento "integração" (Tabela 2); agrupamento "decisões" (Tabela 3) e; agrupamento "relacionamento interpessoal" (Tabela 4). As tabelas 1, 2, 3 e 4 que contém os agrupamentos e suas variáveis estão localizadas no item 4.1 que aborda "Variáveis do estudo: análise quantitativa".

A escala utilizada foi a métrica categorizada em classificação somada (Likert) de sete pontos na qual 1 refere-se a Discordo Totalmente e 7 refere-se a Concordo Totalmente. O questionário foi aplicado à amostragem não probabilística por meio da coleta eletrônica de dados e obteve-se $80,77 \%$ de respostas, ou seja, 21 dos 26 funcionários responderam ao questionário.

No que se refere ao instrumento qualitativo de coleta de dados, utilizou-se a entrevista estruturada. Optou-se por entrevistar um funcionário responsável por cada setor existente, na empresa, para que o processo comunicacional formal interno fosse compreendido em sua totalidade e sem interferências gerencialistas, por isso, as entrevistas foram aplicadas a um funcionário-responsável de cada setor-chave.

Ressalta-se que os setores utilizados, neste estudo, estão classificados conforme subdivisão institucional da organização em estudo. Por isso, para ilustrar a realização das entrevistas com o grupo de funcionários da Associação Comercial e Empresarial pesquisada, elaborouse um Quadro conforme segue (Quadro 1).

Quadro 1 - Setores, para a coleta qualitativa de dados, da Associação Comercial e Empresarial pesquisada

\begin{tabular}{|l|c|}
\hline \multicolumn{1}{|c|}{ Setor } & Amostra de pes quisa \\
\hline \hline Gerência Administrativa & 1 funcionário \\
\hline \hline Junta Comercial & 1 funcionário \\
\hline \hline Secretaria & 1 funcionário \\
\hline \hline Recepção & 1 funcionário \\
\hline \hline Departamento de estágios/ Financeiro/Recursos Hu manos & 1 funcionário \\
\hline \hline Eomercial/ Serviço de Proteção ao Crédito & 1 funcionário \\
\hline \hline Serviços Gerais & 1 funcionário \\
\hline \hline Total & 1 funcionário \\
\hline \hline
\end{tabular}

Fonte: elaborado pelos autores (2017).

Assim, a coleta qualitativa de dados contemplou a realização de oito entrevistas com a duração média, de cada uma das entrevistas, de trinta minutos. Destaca-se que todas as entrevistas foram gravadas com anuência dos participantes da pesquisa e posteriormente, transcritas 
mantendo-se o discurso literal dos entrevistados após limpeza prévia de excesso de irregularidades, ou seja, vícios de linguagem em geral.

A entrevista utilizada foi a estruturada e trata-se de uma adaptação de Vilaça (2012). O roteiro foi composto por questões que abrangem dois eixos centrais temáticos, subdivididos em questões temas que no processo analítico foram agrupadas em dois eixos, conforme segue:

a) Eixo 1 - Comunicação Geral

1. Para você, o que é comunicação?

2. Para você, qual é o papel da comunicação nas empresas?

b) Eixo 2 - Comunicação Interna.

1. Se você tivesse que definir a comunicação interna da Associação em poucas palavras, como seria essa definição.

2. O papel da comunicação na Associação é entendido por todos?

3. E na disseminação de informações dentro da empresa, qual a sua avaliação da comunicação interna?

4. As informações recebidas, atualmente, são suficientes para a execução de suas tarefas?

5. Você já observou que, em alguma situação, alguma tarefa deixou de ser realizada corretamente devido à falta de comunicação?

Vale salientar que os funcionários foram convidados a participar da pesquisa podendo, assim, desistir a qualquer momento sem qualquer dano ou prejuízo, visto que a participação dos sujeitos de pesquisa foi voluntária. Para tanto, o universo desta pesquisa, na parte quantitativa, compõe-se de todos os funcionários da Associação, sem exceção, que totaliza 26 (vinte e seis) funcionários e, na parte qualitativa, compõe-se de 8 (oito) entrevistas, para que o processo comunicacional fosse analisado satisfatoriamente.

A coleta qualitativa de dados, em campo, ainda contemplou a utilização de mais duas técnicas: a observação direta e as anotações de campo que permitiram o registro das informações importantes observadas para que não passassem despercebidas e, também, para que pudessem ser utilizadas na análise dos dados

Referente à análise dos dados, a análise quantitativa delimitada, para o questionário, foi a não paramétrica, elegeu-se como o teste estatístico mais adequado a Análise de Cluster para atender aos objetivos propostos nesta pesquisa. Destaca-se que devido ao fato de o universo de pesquisa ser composto por um número pequeno, as análises paramétricas não se adequaram a este estudo,

No tocante ao tratamento quantitativo dos dados coletados, o mesmo foi realizado por meio de ferramentas estatísticas fundamentadas 
na estatística descritiva com a utilização do pacote estatístico Statistical Package for the Social Sciences (SPSS ${ }^{\circledR}$ ).Já a análise qualitativa foi realizada após a transcrição das entrevistas, por meio de complemento com os registros efetuados durante a observação participante e registrados nas anotações de campo.

\section{Resultados e discussão}

Referente à amostra quantitativa da pesquisa, no que ser refere ao perfil dos 21 respondentes o mais novo indicou ter 19 anos e o mais velho 53 anos. Verificou-se, ainda, que a idade média dos respondentes foi de 31,6 anos e a mediana foi de 29 anos de idade.

Quanto ao estado civil, a porcentagem de solteiros e casados é equitativa e cada um destes representa $38,1 \%$ da amostra, totalizando $76,2 \%$. Assim, os outros $23,8 \%$ representam as outras variáveis (união estável e/ou outro). Em relação ao gênero o predominante foi o feminino com 76,2\% dos respondentes. Desta forma, observa-se um maior predomínio do sexo feminino na instituição.

Em relação à escolaridade, observa-se que $61,9 \%$ da amostra de pesquisa possui ao menos ensino superior. Já as outras opções (ensino fundamental, médio e outro) totalizam $38,1 \%$ dos resultados obtidos. Quanto ao tempo de trabalho na instituição um dos respondentes não informou há quanto tempo trabalha nesta organização e colocou somente a sua carga horária diária na empresa. O sujeito de pesquisa que indicou o menor tempo de trabalho informou que trabalha na instituição há apenas 2 meses. Ademais, o respondente que possui maior tempo de trabalho indicou que trabalha na instituição há 21 anos.

Desta forma, pode-se concluir que o tempo médio de trabalho é de aproximadamente 5 anos e a mediana é de 2,9 anos. No entanto, 65\% dos respondentes são relativamente novos na organização, com menos de 3 anos de trabalho nela, o que pode, eventualmente, ter implicação na percepção do processo de comunicação organizacional.

\subsection{Variáveis do estudo: análise quantitativa}

Em relação às variáveis do estudo (total de 33 variáveis) verificouse que todos os sujeitos de pesquisa, da amostra, responderam a todas as questões, inexistindo dados ausentes. Além disso, a verificação dos dados não identificou a existência de dados extremos (outliers). No entanto, algumas variáveis (Q10; Q15; Q27; Q29; Q31; Q32) foram inseridas no questionário com a escala invertida sendo necessário o ajuste antes do início das análises.

Quanto à análise quantitativa, propriamente dita, como a população é bastante reduzida e, consequentemente, a amostra também, as análises paramétricas ficaram prejudicadas. Desta forma, uma análise mais 
elementar que pode suprir a necessidade deste estudo é a Análise de Cluster para agrupamento hierárquico de variáveis (MARÔCO, 2014). Optou-se por esta técnica para identificar quais fatores (agrupamentos de variáveis) são identificados a partir da amostra da pesquisa. O resultado da Análise de Cluster, utilizando o Método de Ward para agrupamento das variáveis e a Distância Euclidiana Quadrada como medida de semelhança e distância, indicou que as variáveis se agrupam em quatro conjuntos.

Desta maneira as Tabelas 1 a 4 apresentam os agrupamentos de variáveis identificados com fatores nominados de acordo com as características comuns das variáveis que as compõem. Além da média e desvio padrão, também se indicou nas Tabelas o valor do Alfa de Cronbach que se destina a verificar a consistência interna, ou confiabilidade, da escala, tendo em vista que esta é "a medida mais comum de confiabilidade" (FIELD, 2009, p. 594). O teste também indica se existe a necessidade de exclusão de alguma variável em um conjunto para que a consistência interna seja melhorada.

A Tabela 1, referente ao agrupamento "cooperação e objetivos organizacionais", apresenta 16 variáveis:

Tabela 1 - Agrupamento denominado "cooperação e objetivos organizacionais"

\begin{tabular}{l|l|c|c|c|}
\hline \multicolumn{1}{|c}{ Variáveis } & Média & $\begin{array}{l}\text { Des vio- } \\
\text { padrão }\end{array}$ & Alfa \\
\hline Q25 & $\begin{array}{l}\text { A cooperação é fundamental para o bom desempenho das atividades } \\
\text { na organização. }\end{array}$ & 6,90 & 0,301 \\
\hline Q31 & O meu relacionamento com os colegas é difícil. & 6,71 & 0,561 \\
\hline Q30 & Os problemas interpessoais que tenho com os colegas são raros. & 6,57 & 0,676 \\
\hline Q05 & Eu me esforço para que a organização atinja seus objetivos. & 6,67 & 0,658 \\
\hline Q21 & $\begin{array}{l}\text { Eu tenho tido oportunidades de participar de reuniões e/ou encontros } \\
\text { especiais, onde exponho a minha opinão. }\end{array}$ & 6,57 & 0,746 \\
\hline Q32 & $\begin{array}{l}\text { Tenho problemas que dizem respeito ao relacionamento com os } \\
\text { colegas. }\end{array}$ & 6,62 & 0,921 \\
\hline Q09 & Esta organização valoriza os bons princípios. & 6,38 & 1,071 \\
\hline Q19 & $\begin{array}{l}\text { As minhas responsabilidades são comunicadas pela minha chefia } \\
\text { imediata. }\end{array}$ & 6,43 & 1,165 \\
\hline Q03 & Eu acredito nos valores e objetivos desta organização. & 6,38 & 0,669 \\
\hline Q20 & $\begin{array}{l}\text { Frequentemente sou informado (a) sobre o que se passa dentro da } \\
\text { organização. }\end{array}$ & 6,29 & 0,845 \\
\hline Q01 & $\begin{array}{l}\text { A organização, em que trabalho, permite a comunicação entre ela e os } \\
\text { funcionários. }\end{array}$ & 6,33 & 0,856 \\
\hline Q06 & $\begin{array}{l}\text { Existem canais que permitem a comunicação com os funcionários de } \\
\text { todos os níveis }\end{array}$ & 6,05 & 0,865 \\
\hline Q02 & $\begin{array}{l}\text { Eu concordo com as práticas de comunicação com o funcionário, } \\
\text { adotadas pela minha organização. }\end{array}$ & 5,90 & 1,091 \\
\hline Q08 & $\begin{array}{l}\text { Eu sinto que sou incentivado(a) a conhecer todo o negócio desta } \\
\text { organização. }\end{array}$ & 6,19 & 1,365 \\
\hline Q15 & $\begin{array}{l}\text { Não tenho clareza sobre quais são as minhas responsabilidades no } \\
\text { trabalho. }\end{array}$ & 6,67 & 1,317 \\
\hline Eu possuo desagrados em relação a outros membros da organização. & 5,90 & 1,546 \\
\hline
\end{tabular}

Fonte: Elaborado pelos autores (2017) 
A Tabela 1 mostra que a relação entre a menor e a maior média é de 1,0 ponto na escala neste agrupamento. 0 valor encontrado referente ao a de Cronbach $(0,849)$ demonstra consistência interna ou confiabilidade da escala.

Neste caso a exclusão de uma ou mais variáveis não gera ganho significativo no resultado do teste, o que indica que não existe a necessidade de exclusão de nenhuma das variáveis. Desta maneira, é possível supor que este agrupamento acontece de maneira satisfatória na organização em estudo.

Enquanto mais facilitadoras, temos as variáveis relacionadas à cooperação, esforço para atingir objetivos organizacionais, oportunidades de participar de reuniões para expor opinião e valorização de bons princípios pela organização.

No entanto, nas variáveis Q02 e Q27 as médias encontradas foram ligeiramente mais baixas que as outras. Desta forma, a variável Q02 aponta que estes itens podem estar gerando pequenas dificuldades no ambiente. Já a variável Q27 aponta que não há desagrados em relação a outros membros da organização pois a média obtida, apesar de ainda ser elevada, foi mais baixa quando comparada às demais. Porém, neste caso, pode ter havido falha na interpretação da questão, tendo em vista que esta é uma variável mensurada a partir de uma escala invertida.

Ademais, a variável Q15 teve uma média elevada quando comparada às demais deste agrupamento. Neste caso, pode ser visualizada como um fator menos facilitador por evidenciar a possível falta de clareza no desenvolvimento das atividades cotidianas. O mesmo pode ser observado nas variáveis Q31 e Q32 Porém, neste caso, pode ter havido falha na interpretação da questão, tendo em vista que estas são três das variáveis com a escala invertida.

Assim, tais variáveis podem ser identificadas como menos facilitadoras no processo comunicacional interno existente, em relação ao agrupamento "cooperação e objetivos organizacionais", ao observar que nem todos os funcionários concordam com as práticas de comunicação existentes; que afirmam não possuírem clareza sobre as responsabilidades no trabalho e, ainda, relacionamento com colegas foi apontado como difícil.

Visto que a comunicação interna deve ser direcionada a todos os funcionários, sem exceção, para que saibam os interesses gerais da empresa para que se integrem e tenham como incentivo o compartilhamento de informações e o estímulo de experiências e diálogos, a comunicação organizacional interna concentra-se na modificação do comportamento dos funcionários para que se sintam envolvidos com a organização e possam, assim, desenvolver com satisfação suas atividades (RIBEIRO, 2014; CORRADO, 1994). 
A Tabela 2, referente ao agrupamento "integração", apresenta 10 variáveis:

Tabela 2 - Agrupamento denominado "integração"

\begin{tabular}{|c|c|c|c|c|}
\hline \multicolumn{2}{|r|}{ Variáveis } & Média & $\begin{array}{l}\text { Desvio- } \\
\text { padrão }\end{array}$ & Alfa \\
\hline Q14 & $\begin{array}{l}\text { Conversando com os amigos, eu me refiro à minha organização como } \\
\text { uma grande instituição para a qual eu me orgulho em trabalhar. }\end{array}$ & 6,52 & 1,365 & \multirow{10}{*}{$\mathbf{0 , 9 7 0}$} \\
\hline $\mathbf{Q 2 2}$ & $\begin{array}{l}\text { O processo de comunicação nesta organização promove a integração } \\
\text { entre os diferentes setores/departamentos. }\end{array}$ & 6,24 & 1,261 & \\
\hline Q17 & $\begin{array}{l}\text { Nesta organização existem mecanis mos que me permitem falar com } \\
\text { meus superiores diretos, indiretos e colegas. }\end{array}$ & 6,10 & 1,411 & \\
\hline Q07 & Eu gostaria de trabalhar nesta organização por mu itos anos. & 6,05 & 1,396 & \\
\hline Q16 & $\begin{array}{l}\text { Eu sou muito envolvido pessoalmente com o meu trabalho atual porque } \\
\text { a organização me comunica tudo a respeito do seu negócio. }\end{array}$ & 5,67 & 1,713 & \\
\hline Q24 & O processo de comunicação interna na empresa é satisfatório. & 5,33 & 1,683 & \\
\hline Q11 & $\begin{array}{l}\text { Eu gosto de pertencer a esta organização porque sou escutado e sempre } \\
\text { recebo feedback }\end{array}$ & 5,86 & 1,590 & \\
\hline Q18 & $\begin{array}{l}\text { Tenho oportunidade de participar de decisões que afetam o meu } \\
\text { trabalho. }\end{array}$ & 5,67 & 1,653 & \\
\hline Q04 & $\begin{array}{l}\text { Nesta organização a comunicação é vista como importante para o bom } \\
\text { funcionamento do negócio. }\end{array}$ & 6,24 & 1,513 & \\
\hline Q13 & $\begin{array}{l}\text { Eu tenho, nesta organização, oportunidades de me comunicar com a alta } \\
\text { direção. }\end{array}$ & 5,76 & 1,609 & \\
\hline
\end{tabular}

Fonte: Elaborado pelos autores (2017).

A Tabela 2 mostra que a relação entre a menor e a maior média, deste agrupamento, é de 1,19 pontos na escala. O valor encontrado referente ao a de Cronbach $(0,970)$ demonstra consistência interna. Assim, é possível supor que este agrupamento acontece de maneira satisfatória na organização em estudo.

Como mais facilitadores tem-se as variáveis que se referem ao orgulho em trabalhar nesta instituição, integração entre os setores por meio do processo de comunicação e de mecanismos que consentem diálogo com superiores e colegas além de oportunidade de participação em decisões.

Contudo, nas variáveis Q24; Q16; Q18; Q13 e Q11 as médias encontradas foram ligeiramente mais baixas que as outras, indicando que estes são itens que podem estar gerando pequenas dificuldade no ambiente.

Neste sentido, tais variáveis podem ser identificadas como menos facilitadoras no processo comunicacional interno existente, no construto referente ao agrupamento "integração", ao observar que os respondentes subentendem que nem sempre o processo de comunicação pode ser satisfatório, nem todos os funcionários sentem-se envolvidos com o trabalho atual porque nem sempre a organização comunica-Ihes tudo a 
respeito do negócio, nem todos os funcionários possuem oportunidades de participar de decisões que afetam seu trabalho e de comunicação com a alta direção e, ainda, afirmam que nem todos podem ser ouvidos e receber feedback.

Conforme Araujo Filho (2003) ao receber informações, cada funcionário tende a se manifestar sobre elas. Desta forma, cada indivíduo representa tanto um potencial receptor quanto um potencial difusor de opiniões, favoráveis ou não. Evidencia-se, então, a importância da comunicação organizacional interna, para a geração de conhecimento e compartilhamento de informações, estimulando os indivíduos a identificar como a sinergia pode cooperar na maximização dos resultados organizacionais.

Nesse sentido, a gestão eficaz da comunicação interna, almejando a preservação dos inter-relacionamentos, deriva no engajamento dos funcionários com a organização (BEM, 2013). Para tanto, uma boa comunicação interna gera um efeito positivo sobre o ambiente organizacional, sobre os funcionários e a sua opinião sobre a empresa, que é refletida na imagem externa da organização (PAULO, 2012).

A Tabela 3, referente ao agrupamento "decisões", apresenta 3 variáveis:

Tabela 3 - Agrupamento denominado "decisões"

\begin{tabular}{|c|c|c|c|c|}
\hline \multicolumn{2}{|r|}{ Variáveis } & Média & $\begin{array}{l}\text { Desvio- } \\
\text { padrão }\end{array}$ & Alfa \\
\hline Q12 & Eu tenho oportunidades de participar das decisões. & 4,81 & 1,662 & \multirow{3}{*}{0,698} \\
\hline $\mathbf{Q 2 3}$ & $\begin{array}{l}\text { Nesta organização, os funcionários são convidados a participar das } \\
\text { decisões. }\end{array}$ & 4,76 & 1,700 & \\
\hline Q26 & $\begin{array}{l}\text { As divergências pessoais não atrapalham o desenvolvimento do trabalho } \\
\text { dos colaboradores. }\end{array}$ & 5,29 & 1,707 & \\
\hline
\end{tabular}

Fonte: Elaborado pelos autores (2017).

A Tabela 3 mostra que a relação entre a menor e a maior média é de 0,53 . O valor encontrado referente ao a de Cronbach $(0,698)$ demonstra confiabilidade.

Todavia, neste caso, o resultado do teste sugere que a variável Q26 seja retirada das análises para melhoria do Alfa de Cronbach de 0,698 para 0,724. Assim, esta variável será excluída nas demais análises. Desta maneira, é possível supor que este agrupamento acontece de maneira satisfatória na organização em estudo.

Contudo, nas variáveis Q12e Q23 as médias encontradas foram ligeiramente mais baixas, indicando que estes são itens que podem estar gerando pequenas dificuldades no ambiente. Ademais, observa-se que, segundo a percepção dos respondentes, a variável Q23 é o principal item 
menos facilitador do questionário aplicado; tal fator pode ser evidenciado devido ao fato de possuir a média mais baixa das 33 variáveis.

Visto que a variável Q26 foi excluída das análises pode-se observar que este agrupamento não acontece de maneira satisfatória na organização em estudo.

Neste sentido, tais variáveis podem ser identificadas como menos facilitadoras no processo comunicacional interno existente, referente ao agrupamento "decisões", ao observar que nem todos os funcionários afirmam possuir oportunidades de participar das decisões.

A comunicação apresenta-se como um recurso estratégico, pois, as formas de interação nas organizações têm um viés em direção à tomada de decisões, visto que os processos de comunicação em organizações fornecem interessantes conceitos e práticas de diálogo a serem considerados, por exemplo: a globalização dos negócios e o crescimento das mulheres no mercado de trabalho que, desta forma, tornam ativa a diversidade. E, ainda, a discrepância de poder e de relações hierárquicas, que são componentes visíveis na maior parte das grandes organizações (DEETZ; SIMPSON, 2004).

Nesta perspectiva, as organizações precisam de indivíduos qualificados, confiáveis e com elevado espírito de trabalho em equipe, aptos a atuar em equipe e a tomar decisões, em relação às tarefas, com ampla autonomia (GUIMARÃES; SQUIRRA, 2007).

A Tabela 4, referente ao agrupamento "relacionamento interpessoal", apresenta 4 variáveis:

Tabela 4 - Agrupamento denominado "relacionamento interpessoal"

\begin{tabular}{l|l|c|c|c}
\hline \multicolumn{1}{c|}{ Variáveis } & Média & $\begin{array}{l}\text { Des vio- } \\
\text { padrão }\end{array}$ & Alfa \\
\hline $\mathbf{Q 2 8}$ & $\begin{array}{l}\text { Se um colega mostra estar irritado comigo eu converso com ele a } \\
\text { respeito do assunto. }\end{array}$ & 5,14 & 1,682 & \\
\hline $\mathbf{Q 2 9}$ & $\begin{array}{l}\text { Se um colega mostra comportamento de uma maneira diferente eu trato- } \\
\text { o da mes ma maneira, pois, ele prefere assim. }\end{array}$ & 4,90 & 1,814 & $\mathbf{0 , 8 1 2}$ \\
\hline $\mathbf{Q 3 3}$ & Nunca tive problemas de relacionamento interpessoal comos colegas. & 5,29 & 1,953 \\
\hline $\mathbf{Q 1 0}$ & $\begin{array}{l}\text { Eu não recebo informações de outros setores/departamentos da } \\
\text { organização. }\end{array}$ & 5,62 & 1,884 & \\
\hline
\end{tabular}

Fonte: Elaborado pelos autores (2017).

A Tabela 4, que se refere ao agrupamento "relacionamento interpessoal", mostra que a relação entre a menor e a maior média é de 0,72 . O valor encontrado referente ao a de Cronbach $(0,812)$ demonstra confiabilidade.

Todavia, neste caso, o resultado do teste sugere que a variável Q10 seja retirada das análises para melhoria do Alfa de Cronbach de 0,812 para 0,853. Desta forma, esta variável será excluída das demais análises. 
Assim, é possível supor que este agrupamento acontece de maneira satisfatória na organização em estudo.

Como elementos mais facilitadores apontam-se o baixo índice de problemas de relacionamento interpessoal. Contudo, na variável Q29 a média encontrada foi ligeiramente mais baixa que as outras, indicando que este é um item que pode estar gerando pequenas dificuldades no ambiente. Neste sentido, tal variável pode ser identificada como menos facilitadora no processo comunicacional interno existente referente ao agrupamento "relacionamento interpessoal". Porém, também neste caso, pode ter havido falha na interpretação da questão, tendo em vista que esta é uma das variáveis com a escala invertida.

Ressalta-se que, nas organizações, os processos de comunicação interna que estimulem o relacionamento interpessoal são fundamentais para tornar possível o engajamento das relações no ambiente de trabalho (BEM, 2013). Nesta perspectiva, a falta de informações pode ser visualizada como um empecilho ao processo de comunicação, pois, as comunicações internas, nas empresas, devem gerar informações precisas a todos os elementos que a compõe. Desta maneira, pode-se inferir que se refere a um processo de relacionamento (HALL, 2004; CONDIT, 2006).

Nesse sentido, a comunicação refere-se a um rico e complexo processo social que, além de fomentar relacionamentos interpessoais, também os articula, os reproduz e viabiliza (REIS, 2004). Assim, a gestão eficaz da comunicação interna, almejando a preservação dos interrelacionamentos, deriva no engajamento dos funcionários com a organização (BEM, 2013).

Para tanto, uma boa comunicação interna gera um efeito positivo sobre o ambiente organizacional, sobre os funcionários e a sua opinião sobre a empresa que é refletida na imagem externa da organização (PAULO, 2012).

Para verificar a consistência dos dados, na Tabela 5, a seguir, apresenta-se a média total para cada um dos agrupamentos de variáveis, já desconsiderando as variáveis que foram retiradas para melhoria do alfa de Cronbach, segundo indicação do próprio software, na realização do teste, e a mediana.

Tabela 5 - Média e mediana por agrupamento

\begin{tabular}{l|c|c}
\hline \multicolumn{1}{c|}{ Agrupamentos } & Média & Mediana \\
\hline 1 - Agrupamento denominado "cooperação e objetivos" & $\mathbf{6 , 4 1}$ & $\mathbf{6 , 4 4}$ \\
\hline 2 - Agrupamento denominado "integração" & $\mathbf{5 , 9 4}$ & $\mathbf{6 , 3 0}$ \\
\hline 3 - Agrupamento denominado "re lacionamento interpessoal" & $\mathbf{4 , 7 9}$ & $\mathbf{5 , 0 0}$ \\
\hline 4 - Agrupamento denominado "decisões" & $\mathbf{5 , 1 1}$ & $\mathbf{5 , 0 0}$ \\
\hline
\end{tabular}

Fonte: Elaborado pelos autores (2017) 
Conforme dados apresentados, a média apresenta uma variação de 1,62 pontos na escala quando comparadas a maior em relação à menor e o valor da mediana variou relativamente próximo à variação da média (1,44 pontos na escala).

Assim, pelo agrupamento das variáveis, por meio da Análise de Cluster, pode-se inferir que as médias e medianas iguais ou maiores que 5 indicam que os respondentes concordam em grande parte com a afirmativa e estas podem ser consideradas como aspectos que mais facilitam a comunicação. Por outro lado, médias e medianas mais baixas indicam uma discordância com as afirmações e, neste caso, aspectos que podem estar originando pequenos problemas à comunicação.

No caso do grupo "relacionamento interpessoal", que teve sua média próxima a 5 , as questões do grupo indicam baixo grau de concordância, então nota-se que pode haver problemas de relacionamento, identificados mais especificamente a partir da variável Q29. O mesmo acontece com o grupo "decisões" que, neste caso, pode ser identificado como o fator que se apresenta mais próximo de ser um fator dificultador em relação ao demais, especialmente porque neste grupo está a variável com menor média de todas as variáveis incluídas neste estudo: Q23.

Assim, nos agrupamentos "cooperação e objetivos organizacionais" e "integração"; as questões dos grupos indicam que aspectos mais facilitadores podem estar atuando diretamente na comunicação.

$\mathrm{Se}$, por um lado, os dados apontam como fatores menos facilitadores as práticas de comunicação existentes por outro lado fatores mais facilitadores apontam que respondentes afirmaram que frequentemente são informados sobre 0 que se passa dentro da organização. O mesmo acontece, por exemplo, quando os respondentes subentendem que nem sempre o processo de comunicação interna pode ser satisfatório e, ao mesmo tempo, afirmam que o processo de comunicação, na organização, promove a integração entre os diferentes setores/departamentos.

Por meio das informações obtidas em alguns aspectos inseridos em determinados fatores, percebe-se que o processo de comunicação existente acontece de maneira satisfatória, mas, possui alguns itens que deveriam ser aprimorados, visando o aperfeiçoamento da comunicação interna na organização para que os objetivos estabelecidos, pela empresa, sejam atingidos, visando a maximização de resultados. Para Robbins (2005) a comunicação perfeita nunca é obtida na prática. A comunicação perfeita, mesmo que utópica, só aconteceria se um pensamento fosse transmitido de uma pessoa a outra e, ainda, que a figura mental percebida pelo receptor fosse idêntica à do emissor. 
A partir desta ótica, o processo comunicacional de uma organização não é um procedimento simplista e nem fácil de ser analisado, ou seja, envolve vários detalhes que precisam ser verificados com cautela. Não se pode afirmar que o processo comunicacional interno não possua fatores dificultadores, como a pesquisa apontou.

Sabe-se que fatores externos à pesquisa podem dificultar a coleta de dados como, por exemplo: falta de tempo e/ou pressa do respondente; dificuldades de entendimento e/ou percepção do tema ou, ainda, das questões realizadas ou, até mesmo, receio que as informações coletadas sejam identificadas/ divulgadas e que isso prejudique o emprego do pesquisado. Diante de tais fatores aponta-se que o processo de comunicação na Associação possa não ser realmente "tão satisfatório" quanto os sujeitos de pesquisa afirmaram, pois, identificaram-se fatores menos facilitadores no processo existente.

Desta forma, a pesquisa qualitativa foi utilizada em complemento à quantitativa, objetivando identificar tais fatores.

\subsection{Fatores facilitadores e dificultadores na comunicação organizacional interna da associação comercial: análise qualitativa}

Para garantir a preservação da identidade dos entrevistados, os mesmos foram denominados: "A", "B", "C", "D", "E", "F", "G" e "H". O perfil dos respondentes da análise qualitativa é composto, em sua maioria, por indivíduos do gênero feminino. Dos oito entrevistados, cinco são mulheres o que corresponde a $62,5 \%$ da amostra de pesquisa. Já em relação ao grau de escolaridade evidencia-se que $100 \%$ da amostra possui ao menos o ensino médio. Contudo, destes, somente três possuem ao menos o ensino superior, totalizando $37,5 \%$.

A análise qualitativa buscou entender a percepção dos entrevistados sobre a comunicação, bem como, sobre o papel desta nas empresas. Sendo assim, ao serem questionados sobre o que entendem sobre a comunicação, afirmaram:

Comunicação pra mim é o que a gente...o que outro entende, vamos colocar dessa forma. Então, nada mais é que a gente tentar se entender pra resolver qualquer tipo de situação, independente, tanto profissional quanto pessoal e é uma coisa que a gente precisa fazer de uma forma ou de outra, propriamente dito, falando, escrevendo, né? [...] é uma forma de você até se entender com a outra pessoa [...] Então pra mim seria isso, é uma forma das pessoas interagirem (Entrevistado " $\mathrm{A}$ "). 
Comunicação é o meio de expressar o que eu penso, eu sinto. É saber a opinião dos outros...comunicação seria não só eu, mas alguém, colocar, lá, um pensamento, um produto... é uma forma de... vida, é o que a gente faz to do dia ... a conversação, estar em contato (Entrevistado " $\mathrm{B}$ ').

A comunicação hoje, ela é, um dos nossos meios, mais importantes que nós temos. Uma forma de nós nos expressarmos [...] é uma forma da gente se expressar pra que a nossa opinião, a nossa comunicação mesmo, seja realizada de uma forma mais rápida e objetiva (Entrevistado " $\mathrm{C}^{\prime}$ ).

É um meio de uma informação chegar a outro ponto de qualquer tipo, de qualquer forma (Entrevistado " $D$ ").

Comunicação é ... a forma das pessoas interagirem . Acho que seria isso, a pessoa interagir (Entrevistado " $E$ ").

A comunicação é você se comunicar, ficar to do mundo sabendo o que está acontecendo [...] (Entrevistado "F").

Eu entendo que é enviar uma mensagem e ela ser recebida, isso é a comunicação ... alguém que emita e alguém que recebe e seja 0 mesmo entendimento pros dois (Entrevistado " $G$ ").

É as pessoas se comunicarem entre elas trocando informação, alguma situação ... em algum acontecimento (Entrevistado "H").

Por meio da análise dos fragmentos apresentados, verifica-se que não há divergências nas respostas dos profissionais entrevistados, ou seja, apesar de não utilizarem termos explicativos idênticos, possuem a mesma opinião.

Dessa forma, subentende-se que a comunicação envolve interação entre as pessoas; ademais, está presente em todos os relacionamentos humanos. Assim, evidencia-se que a comunicação seja parte integrante da vida das pessoas, independentemente de sua vontade (CARDOSO, 2006).

Por sua vez, ao serem perguntados sobre sua percepção em relação ao papel da comunicação nas empresas, os entrevistados destacam de forma redundante palavras como "importante" e "fundamental". Nesta perspectiva, supõe-se que, pelo menos semanticamente, os entrevistados 
estejam conscientes da relevância da comunicação organizacional para o desenvolvimento das atividades corporativas.

Para tanto, compreender a relevância do processo comunicacional com a finalidade de alcançar o objetivo aspirado é um desafio para as organizações (MELO, 2010).

Num próximo momento foram realizadas indagações relacionadas à comunicação organizacional interna. Para tanto, a questão "se você tivesse que definir a comunicação interna da Associação em poucas palavras, como seria essa definição?"

Evidencia-se, por meio das respostas obtidas, que existem divergências entre as opiniões dos funcionários em relação à comunicação organizacional interna. Enquanto alguns a definem como "excelente", outros a definem como "boa" e, ainda, como "razoável" ou "falha".

A partir das observações realizadas em campo, há como se compreender o porquê destas respostas divergentes. Ou seja, o processo comunicacional interno da organização apresenta falhas em seu percurso que afetam o desenvolvimento das atividades cotidianas tais como: dificuldades na disseminação das informações entre os setores e, consequentemente, falta de informações suficientes para realização de tarefas (DIÁRIO DE CAMPO, 2016).

Todavia, os responsáveis pelos setores percebem estas fragilidades. Neste sentido, quando questionados sobre estes aspectos trazem que:

[..] apesar da gente ter um contato com to do mundo ainda existem algumas falhas, muitas vezes pode ser por parte de quem está passando informação que não esclarece de forma correta e também, da própria pessoa que não entendeu e está querendo resolver $[\ldots]$ (Entrevistado "A").

O entrevistado " $\mathrm{A}$ " expressa, implicitamente, que existem ruídos no processo comunicacional tanto por parte do emissor quanto por parte do receptor. Desta forma, estes fatores podem ser considerados dificultadores no processo de comunicação organizacional.

Assim, faz-se necessário que a comunicação seja entendida, em sua totalidade, para que possa ser executada objetivando minimizar possíveis falhas, pois, a comunicação pode ser visualizada como ações padronizadas a serem aplicadas em processos de mudança organizacional (REIS, 2004).

A Associação adotou como prática, há aproximadamente um ano, a realização de uma reunião semanal que acontece todas as segundasfeiras, às $7 \mathrm{~h} 45$, com os funcionários, em que cada um deles pode expor suas tarefas semanais com o objetivo de que todos os funcionários tenham todas as informações necessárias sobre o desenvolvimento das 
atividades da organização. Contudo, por meio das anotações de campo, observou-se que na prática nem todos os funcionários participam destas reuniões, pois, um funcionário realiza a parte de atendimento ao público e telefônico enquanto os demais participam da reunião semanal. Desta maneira, além do funcionário não expor suas atividades também não ouve o que foi exposto pelos colegas.

Contudo, ao se destacar o repasse de informações na reunião semanal descrita, os entrevistados salientaram que mesmo assim se sentem desinformados. os enunciadores expressam explicitamente que existe a falta de informação no cotidiano organizacional, pois, ao mencionar "a gente fica desinformado", "acontecem coisas [..] que eu nem estou sabendo", "tem muita coisa que eu deveria saber [...] e acabo não sabendo" e "muitas vezes a gente passa por [...] uma situação desagradável de não saber" aponta que existem aspectos a serem aprimorados no processo comunicacional formal interno.

Dessa forma, verifica-se uma divergência de opiniões: enquanto alguns estão satisfeitos com a quantidade de informações que chegam outros se sentem desinformados. Ou seja, observa-se como fator facilitador os meios de comunicação fornecidos pela Associação, aos funcionários, para que o processo de comunicação ocorra da melhor forma possível. Entretanto como fator dificultador no processo comunicacional evidencia-se que os funcionários podem não usufruir de tais meios em sua totalidade, por isso, sentem-se insatisfeitos e/ou não informados.

Para tanto, observa-se que é necessário que o funcionário tenha interesse em realizar a comunicação e o consequente repasse de informações da melhor maneira possível. Isto pode ser observado por meio da percepção de uma entrevistada no fragmento que segue.

[...] as pessoas podem ter todas as informações, mas se ela não fizer o bom uso delas ou não procurar saber mais, é a mesma coisa que não soubesse de nada então ... eu, desde que eu entrei, eu sempre procurei saber 0 departamento comercial faz, o financeiro o que que faz, quais os produtos que a associação, a entidade pode oferecer $[\ldots]$ (Entrevistado " $\mathrm{C}$ ").

Nesse sentido, a dinâmica pela qual se organizam recursos humanos, materiais e financeiros, para alcançar os objetivos delineados, desenvolve-se por meio da interligação dos elementos de uma organização, que são informados e informam continuamente, para a sobrevivência da empresa (KUNSCH, 2003).

Em outras palavras, pode-se dizer que a empresa que se preocupa com a comunicação organizacional de forma integrada é aquela que gera 
sintonia, direcionada aos interesses do cliente interno, qualificando, treinando, introduzindo-o na realidade da empresa (PASSOS, 2010).

Dessa forma, o sistema comunicacional interno é fundamental tanto ao processamento das funções administrativas quanto ao relacionamento das organizações com o meio externo (KUNSCH, 2003). Para tanto, é necessário que os funcionários que a compõem sejam informados sobre o que nela acontece para que consigam desempenhar suas tarefas com qualidade.

Ainda, indagou-se se as informações recebidas, atualmente, são suficientes para a execução das tarefas internas. Por meio das afirmativas dos entrevistados, percebe-se que quatro deles afirmaram receber informações suficientes para execução de suas tarefas. Por sua vez dois afirmaram que não recebem a quantidade de informação necessária para que seu trabalho seja desenvolvido com êxito e, dois mostram-se insatisfeitos ao afirmar que "de zero a dez eu diria sete" e "acho que sim".

Nesse sentido, os desafios relacionados ao processo de comunicação interna, demandam uma nova visão sobre a importância das relações humanas nas organizações; busca-se elevar o senso de equipe, visando a melhoria do clima organizacional, sugestões, ideias e críticas em todos os níveis hierárquicos. Por isso, é fundamental que os processos de comunicação interna que propiciem, nas organizações, o relacionamento interpessoal para originar o engajamento das relações no ambiente de trabalho (BEM, 2013).

Desta forma, quando questionados sobre a falta de realização correta de alguma tarefa devido a falhas na comunicação formal interna, os entrevistados que disseram que isso já ocorreu, contudo, não exemplificaram com situações pontuais e específicas. Considera-se que estes não citaram algum exemplo talvez por sentirem-se "intimidados" com a gravação da entrevista. Explicando de outra forma, após desligar o gravador, 4 dos 8 entrevistados relataram de maneira informal que preferiam não citar exemplo sobre a situação de tarefa não executada de forma correta por receio desta informação "vir a causar algum desconforto dentro do ambiente de trabalho". (DIÁRIO DE CAMPO, 2016)

No tocante aos canais de comunicação interna, utilizados pelos funcionários, os fragmentos que seguem deixam subentendidos pequenos descontentamentos dos entrevistados ao afirmarem que o e-mail corporativo não é a eles disponibilizado:

Eu não tenho acesso ao e-mail [...] Daí as vezes eu pergunto pra eles que que está rolando, pergunto pros colegas (Entrevistado "F") 
[...] a minha parte eu não uso e-mail mas as meninas lá usam... as informações que ficam pra minha parte tem uma menina que é responsável pra passar mas seria interessante ter e-mail (Entrevistado "D").

Ao afirmar que "as vezes pergunto pra eles que que está rolando" evidencia que nem sempre os responsáveis pela transmissão de informações aos funcionários que não possuem e-mail realizam a tarefa da disseminação, pois, se o funcionário que não possui a informação não for buscá-la, pode-se inferir que ela não chegará até ele.

Ademais, essas atitudes consideradas rotineiras como "as informações que ficam pra minha parte tem uma menina que é responsável pra passar" favorecem o surgimento de uma rede de boatos também conhecida como rádio peão ou rádio corredor (KUNSCH, 2003). Cardoso (2009) afirma que os indivíduos possuem necessidade de se comunicar, porém, quando isso acontece de maneira desorganizada origina-se o espaço para as fofocas e ruídos.

Já o fragmento "seria interessante ter e-mail" mostra que o entrevistado tem interesse em utilizar um meio que não foi a ele disponibilizado. Ademais, se é necessário que um funcionário repasse as informações, que foram tratadas via e-mail, aos funcionários que não possuem tal ferramenta, entende-se que as informações são necessárias ao desenvolvimento do trabalho de ambos.

Sendo assim, pode-se afirmar que nem sempre as falhas de comunicação acontecem devido à falta de interesse dos funcionários, mas sim, da alta direção que não trata todos os funcionários com isonomia. $\mathrm{E}$, além da melhor disseminação das informações, os funcionários também poderiam manter-se mais motivados devido ao fato de todos terem o acesso às mesmas informações e simultaneamente.

As organizações devem gerar informações precisas a todos os seus componentes; nesse sentido, refere-se a um processo de relacionamento, visto que não existe vida coletiva nem vida individual sem comunicação. Para tanto, é fundamental conhecer o processo de comunicação organizacional (KUNSCH, 2009; CONDIT, 2006; HALL, 2004; WOLTON, 2004).

Neste sentido, ao adotar uma postura crítica sobre os fatores observados e/ou analisados, observa-se que a Associação acredita estar contribuindo à melhoria do processo comunicacional interno por disponibilizar ferramentas aos funcionários $e$, ainda, nota-se que a gerência visualiza as ferramentas disponíveis como adequadas ao desenvolvimento das atividades cotidianas na organização. No entanto, enquanto alguns funcionários estão satisfeitos outros mostram-se descontentes com algumas destas ferramentas. Assim, pode-se apontar 
que alguns funcionários podem estar encontrando possíveis problemas na utilização destas, ou ainda, subentende-se que fatores ligados ao relacionamento interpessoal podem dificultar o acesso às ferramentas, por isso, tais funcionários acreditam que elas não satisfaçam suas necessidades em sua totalidade.

\section{Considerações finais}

Esta pesquisa teve a pretensão de compreender o processo de comunicação organizacional interna de uma Associação Comercial e Empresarial localizada no Paraná.

Ao comparar a análise dos dados da pesquisa, aponta-se que os resultados trazidos pela pesquisa quantitativa, sobre a operacionalização do processo de comunicação organizacional interna na Associação, mostra que os elementos que mais facilitam a comunicação são os que compõem as variáveis dos agrupamentos "cooperação e objetivos organizacionais" e "integração"; ou seja, as questões dos grupos indicam que não há discordância com as afirmações e, assim, aspectos facilitadores podem estar atuando diretamente na comunicação. Já os agrupamentos "decisões" e "relacionamento interpessoal" indicam que pode haver possíveis problemas de relacionamento, identificados mais especificamente a partir das variáveis Q29 (Se um colega mostra um comportamento de maneira diferente eu trato-o da mesma maneira, pois, ele prefere assim) e Q23 (Nesta organização, os funcionários são convidados a participar das decisões).

Verifica-se que o processo de comunicação formal interno na Associação, de acordo com a pesquisa quantitativa, acontece de maneira satisfatória, pois os fatores possuem médias elevadas e; assim, identificaram-se apenas alguns pontos específicos de possíveis problemas, nas variáveis que possuem as médias baixas; por isso, possui alguns itens que poderiam ser aprimorados. Todavia, destaca-se que a amostra é pequena e que isto dificulta as análises quantitativas.

Por meio da análise qualitativa identificaram-se tanto fatores facilitadores quanto dificultadores no processo comunicacional interno existente. Assim, observou-se que este processo acontece de maneira insatisfatória, ou seja, possui itens que deveriam ser aprimorados e que foram identificados como fatores dificultadores. Tais fatores relacionam-se ao fato de que os respondentes afirmam que nem todos os funcionários possuem acesso aos mesmos canais de comunicação interna (por exemplo, o e-mail) e/ou ao afirmarem estar descontentes com a não disponibilização destas ferramentas. Todavia, como fatores facilitadores do processo comunicacional formal interno, aponta-se os canais de comunicação disponibilizados pela Associação, tais como as reuniões semanais e registros formais em ata e e-mail que evidencia preocupação 
da organização em relação ao desenvolvimento do processo comunicacional.

Observou-se que enquanto a gerência acredita que os canais empregados atendem às necessidades, alguns funcionários não se mostram contentes com as ferramentas de comunicação formal interna disponíveis. Assim, ao observar as práticas de comunicação, adotadas pela organização, verificou-se que os cargos mais elevados no nível hierárquico, como gerência, por exemplo, afirmam que existem canais de comunicação formal utilizados e que atende às necessidades cotidianas. Os canais formais neste caso seriam as reuniões semanais e o e-mail. Contudo, ao observar os cargos técnicos e operacionais, alguns funcionários afirmam que não possuem acesso a estas ferramentas ou estão descontentes com a não utilização destas por eles.

Neste sentido, ao adotar uma postura crítica sobre os fatores observados e/ou analisados, observa-se que a Associação acredita estar contribuindo à melhoria do processo comunicacional interno formal por disponibilizar ferramentas aos funcionários $e$, ainda, nota-se que a gerência visualiza as ferramentas disponíveis como adequadas ao desenvolvimento das atividades cotidianas na organização. No entanto, enquanto alguns funcionários estão satisfeitos outros mostram-se descontentes com algumas destas ferramentas. Assim, pode-se apontar que alguns funcionários podem estar encontrando possíveis problemas na utilização destas, ou ainda, subentende-se que fatores ligados ao relacionamento interpessoal podem dificultar o acesso às ferramentas, por isso, tais funcionários acreditam que elas não satisfaçam suas necessidades em sua totalidade.

Nessa perspectiva, as organizações necessitam observar seus funcionários e suas necessidades e, desta forma, adaptar seu ambiente organizacional. Assim, as estruturas organizacionais, na prática, proporcionam a coordenação das atividades, a gestão das pessoas e o desempenho das organizações (KUNSCH, 2003).

Ao interpretar os aspectos diagnosticados com contribuições teóricas e práticas na organização, com base na literatura sobre o tema e observações coletadas em campo, observou-se que as ferramentas de comunicação interna deveriam ser aprimoradas, visando a integração entre os setores/ departamentos e também a melhor disseminação de informações. Neste sentido, como contribuições práticas, por meio da revisão de literatura realizada e por meio dos dados coletados na pesquisa de campo, visto que alguns respondentes afirmaram não receber informações suficientes para desenvolver seu trabalho. observa-se que as ferramentas de comunicação interna deveriam ser disponibilizadas a todos os funcionários, pois, todos os níveis hierárquicos da empresa precisam 
ter acesso às mesmas ferramentas de comunicação interna: gerência, cargos técnicos e operacionais.

Nesse contexto, conforme Marchiori (2008), a comunicação interna é uma ferramenta estratégica que instiga o diálogo entre lideranças e funcionários, oportuniza o compartilhamento de informações e promove a interação social ao agir no sentido de manter viva a identidade de uma organização.

Desta forma, sugere-se que a Associação realize ações que estimulem a interação entre os funcionários como, por exemplo: atividades interdepartamentais em que os funcionários possam interagir com os outros colegas e também ficar informados sobre as atividades que são desenvolvidas pelos departamentos

Diante do exposto, por meio dos resultados encontrados, conclui-se que o processo de comunicação formal interno na Associação Comercial e Empresarial pesquisada acontece de maneira insatisfatória, ou seja, possui alguns itens que deveriam ser aprimorados, visto que alguns respondentes afirmam não possuírem acesso a determinadas ferramentas de comunicação interna. Ademais, os resultados da pesquisa apontam que a correta utilização de ferramentas de comunicação interna formal é importante, contudo, o uso não pode somente restringir-se à utilização de tecnologias, ou seja, o contato pessoal deve ser mantido.

Assim, verificou-se que todos os níveis hierárquicos e setores da empresa deveriam possuir acesso às mesmas ferramentas de comunicação formal interna para o bom desenvolvimento de suas atividades. Ainda, destaca-se que seria interessante oportunizar a participação de todos os funcionários, sem exceção, das reuniões semanais, evitando a possível desmotivação; utilizar-se da intranet para disponibilizar arquivos eletronicamente.; e, por fim, adotar a comunicação pessoal como facilitadora dos relacionamentos interpessoais.

Torna-se relevante destacar que esta pesquisa, como qualquer pesquisa, não teve a intenção de responder a todas as questões que surgem no que se refere à comunicação organizacional formal interna. Ressalta-se inclusive que os resultados apontados por ela necessitam de novas pesquisas para que os estudos sejam aprofundados.

Como limitação deste estudo aponta-se 0 fato de ser contextualizada em âmbito municipal, trazendo resultado apenas no contexto no qual a Associação se situa.

Como proposta para pesquisas futuras sugere-se identificar a percepção dos funcionários das associações comerciais do Estado do Paraná em relação ao processo comunicacional interno existente. Dessa forma, poderia ser realizado um estudo com base na teoria das redes interorganizacionais. 


\section{REFERÊNCIAS}

ANDRADE, M. C. de. Discurso organizacional: uma pesquisa a ser empreendida entre as áreas de comunicação e administração. Publicatio UEPG: Ciências Sociais Aplicadas, Ponta Grossa, v. 21, n. 1, p. 27-37, ago. 2013.

ARAÚJO FILHO, A. A. de. A Comunicação Interna do Lançamento do "Programa de Segmentação Comportamental e Marketing de Relacionamento Pessoa Física do Banco do Brasil": um estudo de caso. 2003. 271 f. Dissertação (Mestrado em Engenharia de Produção)Universidade Federal de Santa Catarina, Florianópolis, 2003.

BEM, J. C. de. O engajamento e o processo de relacionamento interno mediado pela comunicação nas organizações. 2013. 125 f. Dissertação (Mestrado em Comunicação Social)- Pontifícia Universidade Católica do Rio Grande do Sul, Porto Alegre, 2013.

CARDOSO, M. Quem conta um conto, aumenta um ponto. Observatório da imprensa, n.551, 18 ago. 2009. Disponível em:

http://www.observatoriodaimprensa.com.br/feitos-desfeitas/quem-contaum-conto-aumenta-um-ponto/. Acesso em: 18 mar. 2021.

CARDOSO, O. de O. Comunicação empresarial versus comunicação organizacional: novos desafios teóricos. Revista Administração Pública, Rio de Janeiro, v. 40, n. 6, p. 1123-1144, dez. 2006.

CONDIT, C. M. Communication as relationality. In: SHEPHERD, G. J.; JOHN, J. St.; STRIPHAS, T. Communication as...: perspectives on theory. Thousand Oaks, CA: Sage Publications, p. 03-13, 2006.

CORRADO, F. M. A Força da Comunicação. Trad. Bárbara T. Lambert. São Paulo: Makron Books, 1994.

DEETZ, S.; SIMPSON, J. Critical organizational dialogue: open formation and the demand of otherness. In: ANDERSON, R.; BAXTER, L. A. ; CISSNA, K. N. (Eds.). Dialogue: theorizing difference in communication studies. Thousand Oaks, CA: Sage Publications, p. 141-158, 2004.

FIELD, A. Descobrindo a estatística usando o SPSS. 2. ed. Porto Alegre, RS: Artmed, 2009.

GUIMARÃES, A. S.; SQUIRRA, S. C. de M. Comunicação organizacional e o processo comunicacional: uma perspectiva dialógica. Revista FAMECOS, Porto Alegre, n.33, p. 46-52, ago 2007. 
HALL, R. H. Organizações: estruturas, processos e resultados. 8.ed. Tradução: Roberto Galman. São Paulo: Pearson Prentice Hall, 2004.

KUNSCH, M. M. K. Planejamento de relações públicas na comunicação integrada. 4.ed. rev. atual. e amp. São Paulo: Summus, 2003.

LEMOS, Else. Comunicação Interna como Diferencial em Relações Públicas. In: FARIAS, Luiz Alberto de (org.). Relações Públicas Estratégicas - Técnicas, Conceitos e Instrumentos. São Paulo: Summus, 2011.

LIMA, D. C. A Organização na rede: a influência das novas tecnologias para as relações organizacionais. In: CARDOSO, C. (Org). Comunicação Organizacional hoje II: novos desafios, novas perspectivas. Salvador: Edufba: Gente. 2004.

MARCHIORI, M. Comunicação interna: um fator estratégico no sucesso dos negócios. In: MARCHIORI, M. (Org.). Faces da cultura e da comunicação organizacional. 2 ed São Caetano do Sul: Difusão, p.207224, 2008.

MARCHIORI, M. Os desafios da comunicação interna nas organizações. Conexão - Comunicação e cultura, Caxias do Sul, v. 9, n. 17, p.145-159, jan./jun.2010.

MARCHIORI, M. Reflexões sobre comunicação e relações públicas estratégicas nos ambientes organizacionais brasileiros. Fisec - Estrategias, Buenos Aires, v. 1, p. 104-120, 2011.

MARCHIORI, M.; BULGACOV, S.; VERONEZI, D. P. O. Strategy as generative practice of interaction in a contemporary organization. Fisec Estrategias, Buenos, Aires, v. 2, p. 35-51, 2010.

MARÔCO, J. Análise estatística com o SPSS Statistics. 6ed. Lisboa: Edições Sílabo, 2014.

MARQUES, A. C. S.; MAFRA, R. L. M. Diálogos no contexto organizacional e lugares de estratégia, argumentação e resistência. Organicom - Revista Brasileira de Comunicação Organizacional e Relações Públicas, São Paulo, a.10, n.19, p.82-94, 20sem 2013.

MATEUS, A. Comunicação digital e investigação: a internacionalização da ciência. In: LIVRO DE ATAS DO II CONGRESSO MUNDIAL DE COMUNICAÇÃO IBERO-AMERICANA, 2014, Braga. Anais ... Universidade do Minho, Braga 2014. 
MCPHEE, R. D.; IVERSON, J. Agents of constitution in communidad: constitutive processes of communication in organizations. In: PUTNAM, L. L.; NICOTERA, A. M. Building theories of organization: the constitutive role of communication. Routledge: New York, 2009.

MELO, V. P. C. A comunicação interna e a sua importância para as organizações. 2010. Disponível em: http://docplayer.com.br/89670-Acomunicacao-interna-e-sua-importancia-nas-organizacoes.html. Acesso em: 18 mar. 2021.

NASSAR, P. A comunicação como valor estratégico. In: MARCHIORI, M. (Org.). Faces da cultura e da comunicação organizacional. 2 ed. São Caetano do Sul: Difusão, 2008.

PAULO, A. M. F. de M. O feedback como ferramenta do líder nos processos de Comunicação Interna: estudo de caso da Termalistur E. E. M. 2012. 152 f. Dissertação (Mestrado em Ciências da Comunicação)-Universidade do Minho, Braga, 2012.

PASSOS, S. J. F. dos. A comunicação organizacional e as novas ferramentas midiáticas. Revista Científica da FAI, Santa Rita do Sapucaí, v. 10, n. 1 , p. $94-104,2010$.

PIMENTA, M. A. Comunicação empresarial: conceitos e técnicas para administradores. 7. ed. Campinas, SP: Alínea, 2010.

REBECHI, C. N. Comunicação nas relações de trabalho: análise crítica de vozes na comunicação organizacional no Brasil. 2009, 145 f. Dissertação (Mestrado em Ciências da Comunicação)- Universidade de São Paulo, São Paulo, 2009.

REIS, M. do C. Comunicação e mudança organizacional: uma interlocução instrumental e constitutiva. Organicom - Revista Brasileira de Comunicação Organizacional e Relações Públicas, São Paulo, a.1, n.1, p. 37-53, ago. 2004.

RIBEIRO, E. P. Micronarrativas como estratégia de comunicação interna. 2014. 189 f. Dissertação (Mestrado em Ciências da Comunicação)Universidade de São Paulo, São Paulo, 2014.

RICARDO, C. Comunicação organizacional: estratégias de sucesso? In: CONGRESSO LUSÓFONO DE CIÊNCIAS DA COMUNICAÇÃO, 7, 2009, Lisboa. Anais eletrônicos [...]. Lisboa, 2009. 
SCROFERNEKER, C. M. A. Perspectivas Teóricas da Comunicação Organizacional. Boletín Temático ALAIC - Comunicación para Latinoamérica, a.3, n. 11, jun. 2003.

SOARES, A. T. N. Comunicação e organizações sob influência da complexidade e do risco: uma análise conceitual. In: Eduardo de Jesus; Mozahir Salomão. (Org.). Interações plurais: a comunicação e o contemporâneo. São Paulo: Annablume, 2008.

TAVARES, R. S. de A. Fatores associados ao comprometimento de funcionários de empresas de telecomunicações. 2010. 215 f. Tese (Doutorado em Administração). São Paulo: Universidade de São Paulo, 2010.

TRIVIÑOS, A. N. S. Introdução à pesquisa em ciências sociais: a pesquisa qualitativa em educação. São Paulo: Atlas, 2010.

VILAÇA, W. P. T. A comunicação interna na gestão da sustentabilidade: um estudo fenomenológico. 2012. $291 \mathrm{f}$. Tese (Doutorado em Comunicação)-Universidade de São Paulo, São Paulo, 2012.

WOLTON, D. Pensar a comunicação. Trad. Zélia Leal Adghirni. Brasília: Editora Universidade de Brasília, 2004. 